\title{
Estado y movimientos sociales: Identidades, cruces y estrategias en tensión en América Latina
}

Recibido: 16 de julio 2020 Revisado: 7 de junio 2021 Aprobado: 6 de julio 2021

Hernán Fair Argentino. Doctor en Ciencias Sociales (Universidad de Buenos Aires, Argentina). Investigador Adjunto del Consejo Nacional de Investigaciones Científicas y Técnicas (CONICET) con sede de trabajo en el instituto IESAC de la Universidad Nacional de Quilmes (Argentina). Profesor en la Universidad Nacional de Quilmes (Argentina). Correo electrónico: hernanfair@conicet.gov.ar

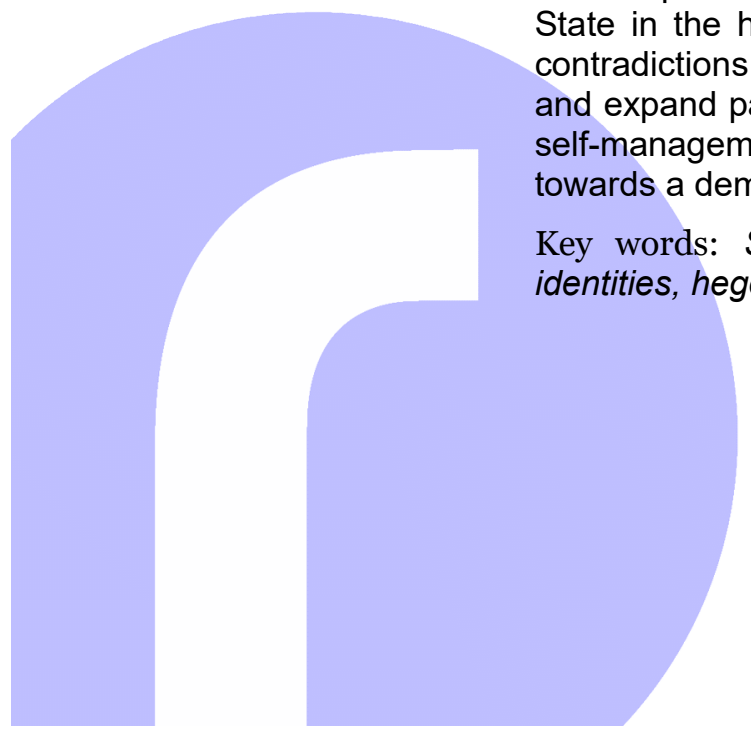
democrático.
Resumen: El presente artículo analiza los cruces entre los movimientos sociales y el Estado en América Latina. Se enfoca en una serie de tensiones en las identidades y estrategias de los movimientos sociales y populares y los gobiernos progresistas: lucha socialista-relaciones de producción capitalistas, mercantilización-desmercantilización, participación horizontal-representación vertical, estrategias articulatorias-estrategias particularistas. En la segunda parte, se analizan los problemas de las estrategias ultraparticularistas y de las concepciones binarias y se indaga acerca del rol del Estado en la disputa hegemónica. En la última parte, se examinan los límites y contradicciones de algunos gobiernos progresistas de la región para radicalizar y ampliar la democracia participativa, fortalecer los modos de autogestión comunitaria y el poder popular, potenciar la desmercantilización y avanzar hacia un socialismo

Palabras clave: Estado y sociedad, movimientos sociales y populares, identidades políticas, lucha hegemónica, democracia radical

\section{State and Social Movements: Identities, Crosses and Strategies in Tension in Latin America}

Abstract: This article analyzes the crosses between social movements and State in Latin America. It focuses on a series of tensions in the identities and strategies of social and popular movements and progressive governments: socialist struggle-capitalist relations of production, commodificationdecommodification, horizontal participation-vertical representation, articulatory strategies-particularist strategies. In the second part, it analyses the problems of ultra-particularist strategies and binary conceptions and the role of the State in the hegemonic dispute. In the last part, it examines the limits and contradictions of some progressive governments in the region to radicalize and expand participatory democracy, strengthen the modes of communitarian self-management and popular power, promote decommodification and move towards a democratic socialism.

Key words: State and society, social and popular movements, political identities, hegemonic struggle, radical democracy 
* Este artículo es patrocinado por el Consejo Nacional de Investigaciones Científicas y Técnicas (CONICET).

\section{Introducción*}

En las últimas décadas asistimos al desarrollo de una pluralidad de modos y formatos de organización social y acción colectiva de las clases y grupos subalternos frente a las formas de explotación y opresión social del orden capitalista, patriarcal, racista, imperialista y colonialista de la Modernidad occidental. América Latina se convirtió en un escenario privilegiado de los combates contra el paradigma dominante, a través de las luchas de los movimientos sociales, indígenas y campesinos, y desde finales de los años noventa, a partir de la acción de los gobiernos progresistas, de centro-izquierda e izquierdas.

El presente trabajo se propone conceptualizar y analizar los cruces y tensiones entre estas identidades y experiencias del campo popular en América Latina. Se enfoca en una serie de tensiones en las identidades y estrategias de los movimientos sociales y populares y los gobiernos progresistas: lucha socialista-relaciones de producción capitalistas, mercantilización-desmercantilización, participación horizontal-representación vertical, estrategias articulatorias-estrategias particularistas.

En la segunda parte, se analizan los problemas de las estrategias ultra-particularistas y de las concepciones binarias y se indaga acerca del rol del Estado en la disputa hegemónica. En la última parte, se examinan los límites y contradicciones de algunos gobiernos progresistas de la región para radicalizar y ampliar la democracia participativa, fortalecer los modos de autogestión comunitaria y el poder popular, potenciar la desmercantilización y avanzar hacia un socialismo democrático.

Democracia radical: organización comunitaria, autogestión social, participación democrática y lucha hegemónica del campo popular en América Latina

Desde una izquierda posgramsciana, que busca construir un socialismo democrático del siglo XXI en clave antiesencialista, se promueven los modos de organización comunitaria, autogestión social, participación democrática y lucha colectiva del campo popular contra las diferentes formas de explotación social y por la liberación de las clases y grupos subalternos oprimidos en el capitalismo actual (Laclau 1993, 2014; Laclau y Mouffe 2004; García Linera 2012). Estas experiencias populares atraviesan varios ejes simultáneos:

a) Por un lado, son formas de organización y lucha socialista que se basan en la autogestión comunitaria de las clases subalternas contra la lógica (discursiva) de mercantilización social, explotación capitalista y dominación imperialista, y que promueven mecanismos de socialización de los medios de pro- 
ducción y participación democrático-horizontal de los grupos subordinados en la gestión económica.

b) Por otro lado, son formas de organización y lucha por la radicalización democrática basadas en la democratización de la participación social a través de criterios igualitarios, horizontales y comunitarios, que promueven la toma efectiva de decisiones públicas por parte de los grupos subalternos más allá del voto igualitario, libre, secreto y universal. Partiendo de la base que "la dimensión de libertad es constitutiva de todo proyecto democrático y emancipatorio" (Laclau y Mouffe 2004, 230), incluimos dentro de la "democracia radical" un sub-eje basado en las formas de democratización ampliadas. Este sub-eje se vincula con los modos de organización colectiva, las luchas sociales y la implementación de políticas públicas que combaten al modelo de dominación patriarcal, colonialista, imperialista, heteronormativo, racista, sexista y xenófobo, y promueven el reconocimiento y aceptación de las diferencias y la pluralidad social que forman parte de la condición humana.

Aunque las luchas políticas y sociales contra la dominación capitalista, imperialista, patriarcal, colonialista y racista están interconectadas entre sí (De Sousa Santos 2017), en este trabajo nos enfocaremos en las experiencias radicalmente democratizadoras de los movimientos sociales y populares y sus cruces con algunos gobiernos progresistas de nuestra América. Siguiendo a Retamozo (2011), desde las premisas de la Teoría Política del Discurso que critica a los enfoques racionalistas y deterministas- el análisis de estos procesos que construyen subjetividades colectivas, sus modos de resistencia, movilización y acción colectiva y las tensiones emergentes, no pueden establecerse a priori o fijarse mecánicamente, sino que deben comprenderse embebidos en su historicidad, y como producto de la dinámica política (discursiva) contingente de la lucha hegemónica.

\section{Las luchas del campo democrático-popular en América Latina: identidades y estrategias en tensión en los movimientos sociales}

En las últimas décadas los sectores subalternos desplegaron en América Latina, con diferentes formatos y grados de radicalización, una pluralidad de formas de organización comunitaria, autogestión social, participación democrática y acción colectiva contra las formas de explotación y opresión social capitalistas, imperialistas, colonialistas, racistas y sexistas (Ceceña 2001; Giarracca y Teubal 2006; Antón Sánchez 2007, Chávez y Mokrani 2007; Curiel 2007; Katz 2008; Gaiger 2009; Lao-Montes 2009; Ouviña 2009; De Sousa Santos 2010; Thwaites Rey 2010; Retamozo 2011; García Linera 2012, 2015; Svampa 2012; Coraggio 2014, 2018; Klachko y Arkonada 2016; Modonesi e Iglesias 2016; Welp 2018; Revilla 2019; Alvarado, Cruz Hernández y Lisset 2020). Al agrupar las diversas modalidades de organización y acción colectiva de los movimientos sociales y populares, identificamos dos estrategias políticas en tensión: 
1. A diferencia de las identidades "parciales", que se basan en reafirmar su propia particularidad, las identidades "con pretensión hegemónica" plantean en términos universalistas sus demandas y aspiran a cubrir el orden comunitario mediante desplazamientos moleculares no segregativos (Aboy Carlés 2013, 34). a) Las estrategias autonomistas y particularistas: Un primer conjunto de experiencias del campo popular desplegó una estrategia autonomista y particularista. Estas experiencias populares se propusieron resguardar una autonomía plena o total frente al Estado y evitaron participar de la competencia electoral. El principal ejemplo de esta estrategia en nuestra región es el movimiento zapatista en México (Ceceña 2001; Modonesi e Iglesias 2016). También se puede situar entre las estrategias particularistas a los estallidos provinciales en la Argentina de los años 90, las movilizaciones sociales de diciembre de 2001 contra la "clase política" (su principal consigna era "¡Que se vayan todos!") y las asambleas barriales y clubes de trueque que surgieron en 2002 y se desvanecieron rápidamente, sin poder estructurar una identidad estable y una propuesta alternativa que condense una nueva subjetividad popular (Katz 2008; Ouviña 2009; Retamozo 2011). Otro ejemplo de estrategias particularistas es la lucha del movimiento estudiantil en Chile contra el modelo neoliberal aplicado a la educación y, con un formato diferente, el movimiento estudiantil \#yosoy132, que emergió en zonas urbanas de México en 2012 contra la manipulación informativa de los medios de comunicación dominantes y por la libertad de expresión, a través de protestas convocadas mediante las nuevas plataformas digitales (Welp 2015, 2018, 216-229). Este tipo de experiencias particularistas se sitúan dentro de lo que Gerardo Aboy Carlés define como identidades populares "parciales", ya que se caracterizan por construir "identidades en disputa con el poder que no aspiran a representar más que su propio espacio" (Aboy Carlés 2013, 31).

b) Las estrategias articulatorias y con pretensiones hegemónicas: en otros casos, los movimientos sociales y populares presentaron sus demandas de un modo más amplio y dialógico (Bajtín 1982). A su vez, construyeron vasos comunicantes y alianzas estratégicas con el Estado para hacer viable, en la correlación de fuerzas, sus demandas primordiales. Estas identidades populares, siguiendo la herencia gramsciana, asumieron una lógica articulatoria y más universalista, con una "pretensión hegemónica"1 (Aboy Carlés 2013). Un ejemplo exitoso de esta estrategia dialógica de organización colectiva y lucha social del campo popular en nuestra región es la del movimiento indígena-campesino en Bolivia, que articuló la lucha anti-neoliberal con la lucha anti-racista, anti-colonialista y por la radicalización democrática. La disputa hegemónica se inició con la marcha por el Territorio y la Dignidad en Bolivia (1990), protagonizada por Organizaciones de los Pueblos Indígenas de Tierras Bajas. Estos sectores interpelaron al Estado para exigirle el reconocimiento de territorios indígenas y de sus organizaciones, así como la titulación de tierras comunitarias de origen. En 1996, a través de la Confederación de Pueblos Indígenas del Oriente Boliviano (CIDOB), los movimientos campesino-indígenas protagonizaron la Marcha Nacional por la Tierra y el Territorio, Dere- 
chos Políticos y Desarrollo (Fernández y Puente 2012). En el año 2000, durante la llamada Guerra del Agua, se generalizó la demanda para conformar una Asamblea Constituyente como lugar de refundación del Estado boliviano, a través del reclamo popular para tener un espacio abierto de encuentro y deliberación colectiva (García Linera 2012). Durante el 2002 los pueblos originarios de Tierras Bajas protagonizaron la Marcha por la Asamblea Constituyente, por la Soberanía Popular, el Territorio y los Recursos Naturales, que reclamó por primera vez la convocatoria a una Asamblea Constituyente (Chávez y Mokrani 2007). La lucha social se intensificó a partir de la guerra contra la privatización del gas (2003), que incluyó una serie de movilizaciones sociales en el altiplano en defensa de los bienes públicos y comunes, y concluyó con la elección popular de Evo Morales (2005), uno de los líderes de aquella disputa hegemónica. Una vez en el gobierno, Morales lideró desde el Movimiento al Socialismo (MAS) la convocatoria a la Asamblea Constituyente, reconoció de un modo participativo e institucionalizó en la nueva Constitución los reclamos históricos de los movimientos indigenista-campesinos (Fernández y Puente 2012). En alianza con los movimientos de base, el gobierno de Morales también lideró un intenso combate contra las formas históricas de discriminación y estigmatización racial de la minoría blanca y rica de la Oligarquía Cruceña hacia las mayorías indígenas y campesinas. En ese marco, garantizó la igualdad de trato y de participación a los pueblos originarios, haciendo cumplir sus derechos comunitarios negados. Su primera medida, a comienzos de 2006, fue convocar a una Asamblea Constituyente que recogió las demandas postergadas de los movimientos sociales y conformó un Estado plurinacional, que otorgó autonomía y participación a las mayorías indígenas y promovió la diversidad social y cultural (García Linera 2012; Coraggio 2014). La asamblea constituyente institucionalizó las demandas históricas de los movimientos indígenas y campesinos contra el colonialismo y el racismo y en defensa de la plurinacionalidad y la interculturalidad (De Sousa Santos 2010, 2017). En esta línea, la Asamblea popular estableció formas de democracia directa desde las bases y tipificó mecanismos de participación comunitaria para los pueblos originarios (Chávez y Mokrani 2007). Junto con el derecho a la elección popular de asambleístas, ese año el dirigente Aymara convocó a tres referéndums autonómicos y, durante el 2008, aprobó una revocatoria de mandato regional. El 25 de enero de 2009 el gobierno de Evo empleó el referéndum popular para reformar la Constitución Nacional. El 7 de febrero de 2010 promulgó una nueva Constitución, que profundizó los canales de participación popular de los pueblos originarios y los vasos comunicantes con el Estado. Además, estableció la elección directa de asambleístas, quienes conformaron instituciones deliberativas capaces de aprobar leyes. Morales también satisfizo la principal demanda 
de los movimientos indigenistas-campesinos, al nacionalizar los $\mathrm{Hi}-$ drocarburos (García Linera 2012; Klachko y Arkonada 2016).

Un segundo ejemplo es el caso de Ecuador. En este país, los pueblos del sur y del norte amazónico se articularon desde los años ochenta a través de tres tipos de organizaciones de base (comunas, cooperativas y asociaciones), mediante un modo de funcionamiento autónomo y descentralizado, bajo una modalidad asamblearia. Organizados en la Confederación de Nacionalidades Indígenas de la Amazonia Ecuatoriana (CONFENIAE), lideraron durante los noventa la lucha social por la reconstitución de sus territorios, contra la explotación petrolera, forestal y agroindustrial y la degradación ecológica. En ese marco, realizaron masivas movilizaciones y protestas sociales contra el neoliberalismo (Marcha por los Territorios y por la Vida, Movilización por la Vida) y en defensa de los derechos de los pueblos originarios, que se iniciaron con el levantamiento popular de la CONAIE en 1990 y condujeron a la creación del Movimiento de Unidad Plurinacional Pachakutik, en 1995. Los movimientos sociales de base mantuvieron una lógica dialoguista y negociadora con el gobierno de Rafael Correa y, a partir de la Alianza País, lograron el reconocimiento de sus demandas colectivas, a través de la participación en la redacción de la Asamblea Constituyente y la tipificación de sus reclamos históricos (Fernández y Puente 2012). En este sentido, Correa convocó en 2007 a una Asamblea Constituyente, que institucionalizó desde abajo los derechos sociales e interculturales que reclamaban históricamente los pueblos originarios (Klachko y Arkonada 2016, 159-160). Además, garantizó la conformación de gobiernos territoriales comunitarios, administrados por estructuras de autoridad autónomas (Fernández y Puente 2012).

\section{Los límites de las luchas ultra-particularistas en América Latina}

\section{Los problemas estratégicos de la praxis social}

Pese a sus valiosos modos de organización democrática y acción colectiva en defensa de las clases subalternas, en América Latina los movimientos autonomistas tuvieron fuertes limitaciones para viabilizar una alternativa política concreta al sistema de dominación. Estas experiencias del campo popular construyeron identidades particularistas que privilegiaron la negatividad frente al orden dominante y la plena autonomía mítica de lo social. Ello implicó una serie de problemas estratégicos, interconectados entre sí:

Monologismo y sectarismo político: al mantener una lógica autonomista, los movimientos sociales asumieron una estrategia sectaria y monologal (Bajtín 1982). De este modo, no lograron articular sus diferentes demandas particulares de un modo más universalista, condición de posibilidad del éxito político.

Lógica defensiva y ausencia de proyectos alternativos: se enfocaron en una lógica defensiva de crítica frente al orden vigente. De esta manera, desdibujaron la construcción de una alternativa programática desde el plano de 
la positividad. Debemos tomar en cuenta que, como señalan Laclau y Mouffe, ninguna operación hegemónica es exitosa si no logra trascender la negatividad frente al orden vigente y construye estrategias alternativas de positivación (Laclau y Mouffe 2004, 235).

Demonización del Estado, la negociación política y la competencia electoral: los movimientos autonomistas tendieron a demonizar al Estado y la competencia electoral. Si bien es cierto que dentro del sistema capitalista el Estado encuentra limitaciones estructuradas para avanzar en una dirección anti-capitalista, los movimientos autonomistas esencializaron al Estado como enemigo a priori de las clases subalternas. Este modo de razonamiento simplificante debilitó la fuerza performativa y la eficacia de sus reclamos históricos, al no contar con el poder vinculante que se deriva de la institucionalización de los derechos sociales, garantizados por la coacción estatal.

Como resultado de este modo de estructuración defensivo y ultra-particularista de las identidades, las luchas autonomistas no lograron modificar de un modo efectivo la correlación de fuerzas sociales. De esta forma, como una consecuencia no buscada de sus acciones, terminaron siendo de algún modo funcionales a la perpetuación de las condiciones de explotación vigentes. La fallida experiencia de las Asambleas barriales, en la Argentina del 2002, muestra los límites fenoménicos de estas experiencias de "autonomismo ingenuo" (Ouviña 2009).

Estos problemas de estrategia política no invalidan la importancia de las luchas autonomistas, que contribuyeron a democratizar las relaciones sociales desde una lógica horizontal (Ceceña 2001; Modonesi e Iglesias 2016). Tampoco desconocen el peligro de "transformismo" (Gramsci 1984) y cooptación estatal. Pero sí muestran limitaciones relevantes para reconocer algunos avances graduales de los gobiernos democrático-populares, aunque estos sean parciales, limitados, relativos y, con frecuencia, contradictorios. Además, menosprecian el auxilio que, en ciertas circunstancias, puede tener el Estado Social para reconocer sus demandas primordiales y modificar la correlación de fuerzas del capitalismo en favor de las clases subalternas (Fair 2017).

\section{Las tensiones irresueltas en las democracias actuales}

A partir del análisis de las experiencias radicalizadas de lucha social de los sectores subalternos en nuestra América, identificamos dos tensiones irresueltas:

1. La tensión participación horizontal - representación vertical: como lo han destacado García Linera (2012) y Laclau (2014), existe una tensión entre las formas decisionistas-verticalistas desde arriba del Estado y el régimen de democracia representativa; y las formas participativas-horizontales desde abajo de los movimientos sociales. El creciente "avance de formas de protesta social que escapan a toda obvia domesticación institucional" (Laclau 2014, 19) reenvía a un problema histórico de la visión clásica de la democracia: la tensión entre 
2. Como señala Laclau, aunque la teoría de la democracia de Rousseau era "recelosa" de la representación, al mismo tiempo la aceptaba como un "mal menor", "dada la imposibilidad de una democracia directa en comunidades grandes, como los modernos Estados Nación" (Laclau 2005, op. cit., p. 200). el ideal de autogobierno del demos; y la inevitabilidad de ciertas formas ónticas de representación política de lo social (ya reconocidas por el propio Rousseau²). El problema se agrava en las complejas democracias contemporáneas, en condiciones de amplia población y extensión territorial y con múltiples y fragmentadas identidades, intereses y demandas sociales (Manin 1998).

2. La tensión lucha socialista y anticapitalista - relaciones sociales capitalistas: esta segunda tensión se vincula con el deseo de promover prácticas anti-mercantiles, anticapitalistas y socializantes, basadas en el valor de uso, la solidaridad, la reciprocidad y la satisfacción de necesidades; y el modo de funcionamiento fáctico del sistema capitalista, con su lógica (discursiva) mercantilista e instrumental subyacente y fuertemente estructurada históricamente, centrada en el valor de cambio, la maximización ilimitada del lucro privado y la explotación del trabajo asalariado.

\section{La lógica política simplificadora y las falsas disyunciones binarias}

Estas tensiones encuentran un problema adicional cuando son abordadas desde una visión epistemológico-política binaria, que reduce las opciones a una lógica de todo o nada. En primer lugar, en relación a la tensión participación-representación, se debe considerar que para poder viabilizar los reclamos históricos de las clases subalternas en las democracias realmente existentes, no es posible abandonar plenamente las mediaciones institucionales. Así, frente a las limitaciones ontológico-estructurales para alcanzar la plena presencia del Demos, se debe reconocer la inevitabilidad de ciertas formas de representación política e institucionalizada.

Sin embargo, la dicotomía binaria asamblea popular versus parlamentarismo, o democracia obrera versus democracia burguesa, es falsa. Así como institucionalización no implica administrativismo tecnocrático -y socialismo no equivale a estatismo ni a populismo (De Ípola y Portantiero 1981)- la inevitabilidad de ciertas mediaciones institucionales no implica necesariamente reducir la representación política a los estrechos márgenes del procedimentalismo liberal, ni tampoco caer en un mítico administrativismo - gestionario. Existen diversos mecanismos intermedios de participación directa y semi-directa del demos, desde las formas asamblearias y los consejos comunales, hasta los referéndums, plebiscitos, consultas e iniciativas populares, las revocatorias de mandatos y los presupuestos participativos, que permiten radicalizar la democracia y extender la participación popular (Macpherson 2012; Pateman 2014; Schneider y Welp 2011; Blondiaux 2013; Welp 2018), y que han sido utilizados principalmente por los gobiernos de Chávez, Evo Morales y Correa. Ello permite superar la falsa disyunción entre participación horizontal-representación vertical, e ir hacia formas más complejas de democracia participativa, dentro de los sistemas de democracia representativa vigentes. 
Este camino de superación de los falsos binarismos es el que Laclau (2014) propone en su último escrito, cuando vincula la propuesta del Socialismo del siglo XXI con la necesidad de "avanzar paralelamente" en la dimensión "vertical" de la hegemonía y la dimensión "horizontal" de los movimientos sociales. Ello para evitar el doble peligro de dispersión particularista de las luchas sociales y de cooptación y burocratización por parte del Estado:

La dimensión horizontal de la autonomía sería incapaz, si es librada a sí misma, de lograr un cambio histórico de largo plazo, a menos que sea complementada por la dimensión vertical de la hegemonía, es decir, por una radical transformación del Estado. La autonomía, librada a sí misma, conduce, más tarde o más temprano, al agotamiento o la dispersión de los movimientos de protesta. Pero la hegemonía, si no es acompañada de una acción de masas al nivel de la sociedad civil, conduce a una burocratización o a una fácil colonización de las fuerzas del status quo. Avanzar paralelamente en las direcciones de la autonomía y de la hegemonía es el verdadero desafío para aquellos que luchan por un futuro democrático que dé un real significado al -con frecuencia advocado- socialismo del siglo XXI (Laclau 2014, 20; el subrayado y las negritas son propias).

En cuanto a la tensión mercantilización-desmercantilización, aunque es cierto que la lógica del juego capitalista condiciona fuertemente el accionar de los agentes, se debe considerar que existen en América Latina diversas experiencias poscapitalistas y comunitarias viables que se mantienen en los márgenes del sistema de dominación. Desde las cooperativas sociales, las mutuales y las fábricas y empresas autogestionadas por las/los trabajadoras/es, hasta las formas de Economía Social y Solidaria (ESS), economía ecológica, economía popular, economía comunitaria, economía feminista, economía plural, agricultura familiar y producción familiar para el autoconsumo (Gaiger 2009; López Castro y Prividera 2011; Coraggio 2014, 2018; Ruggeri 2014; Bruno, Coelho y Palumbo 2017; López Castro 2017; Maldovan Bonelli 2020). Ello permite superar las falsas disyunciones binarias e ir hacia formas mixtas de autogestión obrera, organización comunal y socialización parcial de los medios de producción, basadas en una "reproducción no-capitalista" (García Linera 2015, 83 y ss.). 


\section{El rol del Estado y la acción estratégica en la disputa por la hegemonía}

Las tensiones que analizamos en los apartados anteriores se entrecruzan con un eje central de discusión, que se vincula al rol del Estado. La lógica binaria de los movimientos autonomistas considera al Estado como un enemigo a priori. Sin embargo, entre el decisionismo estatal y la plena autonomía societal, existen puntos intermedios que permiten diferentes vías de negociación estratégica y habilitan diferentes grados de dialogismo.

En primer lugar, en el marco de la existencia de Estados-Nación que cuentan con el poder de institucionalizar derechos sociales y de utilizar su aparato coercitivo para ejercer el monopolio de la violencia física con pretensiones legítimas para cumplimentar sus ordenanzas, no puede ignorarse la relevancia crucial del Estado en la lucha hegemónica (Thwaites Rey, 2010).

Como aconteció con las demandas por el matrimonio igualitario y la despenalización del aborto en la Argentina, y las luchas históricas de los movimientos indígenas-campesinos en Bolivia y Ecuador contra la discriminación y la mercantilización de los bienes públicos y comunes y por el reconocimiento intercultural, en ocasiones el accionar del Estado puede contribuir a reconocer y dar voz a las demandas primordiales de las minorías sociales y los grupos marginados por el sistema de dominación. De este modo, en ciertos casos el Estado Social es capaz de garantizar, al institucionalizar y regular desde la fuerza pública, el cumplimiento efectivo de los derechos elementales de los sectores subalternos.

Al asumir que el Estado es el enemigo ontológico de las clases subalternas, no sólo se dejan a un lado los diferentes modelos de desarrollo en pugna y sus efectos diferenciales para el fortalecimiento o debilitamiento de las/los trabajadoras/es y el poder popular. Además, se impide pensar en la potencialidad del Estado para canalizar democráticamente ciertas demandas sociales de las clases y grupos subalternos que históricamente fueron explotados, discriminados y estigmatizados por las elites dominantes.

El antagonismo esencialista centrado en el Estado pierde de vista que el principal beneficiado de la retirada del Estado Social es el capital concentrado, tanto el financiero-especulativo, como el primario-exportador. Las políticas neoliberales de apertura y desregulación económica indiscriminadas destruyen a las/los pequeñas/os productoras/es rurales y a las pymes vinculadas al mercado interno, e intensifican la concentración del ingreso y la centralización del capital. Las políticas de "flexibilización" laboral potencian los niveles de explotación, acentúan la marginalidad y aniquilan los derechos sociales básicos de las/los trabajadoras/es. Las medidas de ajuste fiscalista deterioran las condiciones de trabajo, la salud y la calidad de vida de las clases subalternas, mientras que la privatización de los bienes públicos y comunes profundizan el desempleo y la exclusión social (Harvey 2007).

La concepción binaria del todo o nada, además, deja a un lado la posibilidad estratégica de fomentar mecanismos de socialización mixta y cogestión de 
los medios de producción, que promuevan crecientes grados de desmercantilización y autonomía social ${ }^{3}$. También deja de lado la reflexión sobre las diferentes formas de democracia participativa y poder popular que van más allá del procedimentalismo liberal, sin caer en la nostalgia mítica de la pura presencia del demos. Tomar en cuenta estas cuestiones requiere reflexionar sobre las modalidades de participación comunitaria y poder popular en las circunstancias concretas del capitalismo actual, signadas por una mayor extensión territorial, tamaño y población, creciente fragmentación de intereses y demandas y heterogeneización de las identidades.

3. Ello no implica que las tensiones con la lógica de producción y reproducción social capitalista sean resueltas Como señalan Bruno, Coelho y Palumbo (2017), en relación al caso de la Confederación de Trabajadores de la Economía Popular (CTEP) en la Argentina: "La tensión entre la necesidad de afirmar prácticas colectivas a

Pero el principal problema de la estrategia binaria es que impide modificar de un modo efectivo la correlación de fuerzas sociales. Al mantener una estrategia ultra-particularista y monologal, estas identidades parciales pierden de vista la importancia central que, desde Gramsci a Laclau, presenta la construcción hegemónica y su lógica de articulación social en voluntades colectivas más amplias. La articulación política resulta crucial, ya que permite amalgamar las diversas demandas e intereses de los grupos subalternos en torno a un mismo proyecto. En cambio, la estrategia ultra-particularista y anti-estatista condujo históricamente a las clases subalternas a una resistencia meranivel territorial y comunitario (a menudo, oponiéndose al Estado) y la "dependencia" con el poder estatal para llevarlas adelante, va a generar una tensión entre heteronomía y autonomía estatal que atravesará y acompañará las experiencias de las organizaciones del campo popular" (op. cit., p. 98). mente defensiva. Esta lógica no sólo invisibilizó sus demandas emancipadoras, sino que además restringió la capacidad de combatir con éxito al sistema de dominación.

A partir de estas consideraciones teóricas sobre la praxis política, entendemos que resulta importante repensar una serie de aspectos cruciales de la lucha de poder, para contribuir a viabilizar un proyecto socialista y democrático del siglo XXI:

a) Ante la inevitabilidad de ciertas formas de representación política, la posibilidad de realizar algunas vinculaciones estratégico-políticas con el Estado para viabilizar los reclamos históricos de los sectores subalternos. El Estado, en ese sentido, deja de constituir un enemigo a priori, para ser entendido -en ciertas condiciones- como un potencial aliado estratégico de las luchas sociales de las clases subalternas.

b) La posibilidad estratégica de tomar en cuenta los mecanismos institucionales tradicionales que sirven para canalizar las demandas sociales de los grupos subalternos, como los sindicatos y partidos políticos, aunque procurando preservar una lógica lo más horizontal, igualitaria, participativa y plural posible. Ello requiere preservar ciertos grados relativos de autonomía para fomentar el poder popular desde abajo y garantizar la máxima igualdad social del demos, junto con el máximo grado de reconocimiento y aceptación de las particularidades y diferencias internas, para evitar el riesgo de burocratización y cooptación transformista de las clases subalternas.

c) La posibilidad estratégica de articular formas mixtas de producción, organización y autogestión social de las clases subalternas, a través 
de una lógica desmercantilizadora, solidaria, comunitaria y no estrictamente capitalista.

d) La posibilidad estratégica de articular las luchas sociales de las clases subalternas y promover una estrategia política ofensiva frente al orden capitalista. Ello supone ir más allá de la crítica sectaria y simplista al Estado "burgués", para reconocer que existen en el capitalismo diferentes modelos de desarrollo con grados diferenciales de desmercantilización y democratización popular, y con efectos muy distintos sobre las condiciones de vida y los derechos fundamentales de las clases subalternas. La estrategia ofensiva implica, además, construir un programa político que, preservando las particularidades y diferencias sociales, intente articular solidariamente las demandas e intereses fragmentados del pueblo trabajador, para enfrentar al bloque de poder.

\section{Los límites y contradicciones de los gobiernos progresistas de América Latina}

Si los movimientos autonomistas no lograron modificar la correlación de fuerzas sociales con su estrategia ultra-particularista, los gobiernos progresistas y de (centro)izquierdas de América Latina mostraron, con diferentes grados e intensidades, importantes limitaciones ónticas para radicalizar la democracia y profundizar el poder popular.

En relación con la tensión participación horizontal/representación vertical, diversas/os autoras/es criticaron, principalmente en los casos de Venezuela y Argentina, las prácticas verticalistas, centralistas, personalistas y decisionistas (desde arriba) de los gobiernos populares, así como el uso de mecanismos de cooptación, clientelismo, transformismo y control social, que atentan contra la lógica democrático-horizontal, ampliamente participativa, plural y ascendente (desde abajo) que debe primar en el proceso de democratización social y empoderamiento popular (López Maya 2010; Thwaites Rey 2010; De Sena y Chahbenderian 2011; Goldfrank 2011; Schneider y Welp 2011, Coraggio 2014, entre otras/os). En las comunas y consejos comunales, por ejemplo, el chavismo mostró a partir del 2006 una dinámica de imposición "de arriba hacia abajo", que "redujo y partidizó el pluralismo comunitario que era propio de las organizaciones impulsadas en el primer gobierno de Chávez". Esta dinámica limitó su potencial autonómico y propició su cooptación vertical (López Maya 2018, 60 y ss.).

Por otra parte, en contraste con los ejemplos radicalizados de Bolivia, Ecuador y Venezuela, en los gobiernos progresistas de Sudamérica no se implementaron asambleas populares constituyentes ni consejos comunales y, con excepción de Uruguay, tampoco hubo referéndums populares (Welp 2018). Con la excepción de Brasil, en estos países tampoco se extendieron las experiencias de Presupuesto Participativo, más allá de formas micro-locales 
cuyo porcentaje de democratización de los recursos públicos carece de relevancia efectiva.

En relación con la tensión mercantilización-desmercantilización, la literatura especializada criticó en particular a los gobiernos de Néstor y Cristina Fernández de Kirchner y "Lula" Da Silva y Dilma Rousseff por la continuidad de políticas neoliberales que potenciaron la concentración económica y la centralización del capital e intensificaron los altísimos niveles de pobreza, precarización e informalidad laboral (Katz 2008; Sader 2009, Marticorena 2013; Gaggero, Schorr y Wainer 2014; Belloni y Wainer 2014; Wainer y Schorr 2014; Bringel 2017). También se ha criticado a los gobiernos progresistas en general por convalidar un modelo de explotación extractivista basado en la acumulación por desposesión, que reprimariza la economía a partir de la expansión del agronegocio y la mega-minería transnacional, concentra la propiedad de la tierra y expolia los bienes públicos y comunes (Svampa 2011, 2012; Seoane 2012; Coraggio 2014). De allí que diversos autoras/es definan como posneoliberal o neodesarrollista, a estos gobiernos democrático-populares que emergieron de la crisis del orden neoliberal (Fair 2020).

En cuanto a las formas de democratización ampliadas, en el caso de Argentina, una parte de la bibliografía denunció la persecución, criminalización y represión de la protesta social durante el gobierno kirchnerista contra la comunidad Qom en la provincia de Formosa y contra otros pueblos originarios, el paradigma securitario y la represión indiscriminada de las luchas obreras, así como la cooptación de dirigentes sociales y organismos de Derechos Humanos (Katz 2008; Svampa 2011; Castillo y Castilla 2015).

En Venezuela se denunció el cierre de medios de comunicación anti-chavistas (o anti-Maduro), la detención arbitraria de alcaldes opositores y el asesinato policial de estudiantes que protestaban contra el gobierno; mientras que en Brasil, país también federal, se criticó la militarización y criminalización de la protesta social por parte del Gobierno del PT y su Coalición (Sader 2009; Bringel 2017).

Por otro lado, la mayor parte de los gobiernos populares de la región no sancionaron el derecho al matrimonio igualitario, al aborto, a una muerte digna (eutanasia) y a la fertilización asistida, y en Bolivia la Convención Constituyente no realizó un debate serio sobre la problemática de género, mientras que en Ecuador Correa rechazó debatir sobre el aborto por razones constitucionales (Welp 2018, 340).

A partir del análisis óntico-fenoménico de estas experiencias históricas, encontramos una serie de contrastes y contradicciones atributivos entre los aspectos interpelativos (la prédica) de los gobiernos progresistas y de centro-izquierdas de América Latina; y el estilo fáctico de ejercer el poder, las políticas públicas y las prácticas sociales (discursivas) de estos mismos gobiernos:

a) El contraste entre una prédica nacional-popular y anti-neoliberal (en algunos casos, con una retórica socialista y anti-capitalista); y la aplicación fáctica de prácticas sociales y políticas públicas mercantilistas 
y neo-extractivistas, que profundizan los niveles de transnacionalización, extranjerización y reprimarización económica e intensifican la concentración del ingreso y la centralización del capital.

b) El contraste entre una prédica de inclusión social del Pueblo, protección de los trabajadores y ampliación de derechos sociales universales que se opone al modelo neoliberal; y la aplicación de políticas públicas desreguladoras, privatizadoras y asistencialistas que promueven, por acción u omisión, crecientes niveles de explotación y precarización de la mano de obra asalariada y preservan (y en ocasiones acentúan) altísimos índices de pobreza, inequidad social, informalidad laboral, marginalidad y exclusión social, en una línea de continuidad con el proyecto neoliberal.

c) El contraste entre una prédica en defensa de la solidaridad y la inclusión social, lucha contra el individualismo, la lógica mercantilista y privatizadora del capitalismo neoliberal y defensa de la naturaleza y la biodiversidad, y la persistencia de prácticas sociales y políticas públicas que potencian la acumulación por desposesión y la degradación del medio ambiente, acentúan la mercantilización y la financiarización económica, naturalizan la competencia feroz, el individualismo-egoísta y la maximización ilimitada del lucro privado.

d) El contraste entre una retórica de democratización social horizontal y gobierno para el Pueblo y 'los de abajo'; y la persistencia fáctica de prácticas burocráticas, personalistas, verticalistas y centralistas, basadas en la toma de decisiones desde arriba y con escasa democratización social.

Estas tensiones y contradicciones atributivas no invalidan los avances graduales realizados por los gobiernos populares. Sin embargo, muestran algunas inconsistencias y limitaciones relevantes que no pueden soslayarse. En parte debido a estas limitaciones, en los últimos años asistimos en varios países de América Latina al retorno de gobiernos de corte neoliberal y conservador que fueron votados y avalados democráticamente a partir de un discurso reaccionario contra los gobiernos progresistas y de centro- izquierdas.

\section{A modo de conclusión}

Pese a sus valiosos avances en el grado de desmercantilización y democratización social, los gobiernos progresistas y los movimientos sociales y populares en América Latina de nuestro tiempo mostraron -con diversos matices e intensidades- importantes limitaciones históricas para radicalizar y ampliar la democracia participativa, potenciar los modos de autogestión comunitaria y el poder popular y construir una alternativa antagónica al sistema de dominación. Estos límites se vinculan con tres tensiones irresueltas. En primer lugar, la tensión que existe entre el deseo de socializar los medios de producción, desmercantilizar los bienes públicos y comunes, promover la solidaridad colectiva y superar las formas de explotación de las clases subalternas del capi- 
talismo; y la existencia fáctica de un sistema capitalista de dominación cuyos valores híper-mercantilistas e instrumentalistas basados en la acumulación ilimitada y la maximización del lucro se encuentran fuertemente arraigados socialmente, y cuyos actores de poder predominantes a nivel nacional y mundial se aferran con todas las fuerzas para promover su perpetuación.

En segundo término, la tensión que existe entre el deseo de incrementar lo máximo posible los niveles de participación social y autogestión popular, horizontal, igualitaria y desde abajo del demos; y la inevitabilidad de ciertos mecanismos de representación política y decisión vertical. Por último, la tensión entre la defensa de un sistema democrático basado en el principio de la igualdad; y la necesidad de reconocer las diferencias y aceptar la pluralidad social.

Desde una izquierda "no fundamentalista", no existe una única solución objetiva, un método "mágico", ni un camino universal o predestinado para resolver estos problemas de la praxis histórico-social. Sin asumir un voluntarismo ingenuo, su respuesta depende en gran medida de la construcción política y del análisis riguroso de la correlación de fuerzas sociales prevalente, en determinado tiempo y espacio.

En estas condiciones, resulta crucial continuar discutiendo de un modo amplio y plural para contribuir a edificar un proyecto colectivo, capaz de promover de un modo efectivo la igualdad social, fortalecer la participación comunitaria y autogestionaria del demos, profundizar la solidaridad social y luchar por la liberación de las clases y grupos subalternos explotados y oprimidos en el capitalismo actual. Ello sin caer en posiciones esencialistas, dogmáticas, elitistas o ilustradas, y sin desconocer el mosaico de diferencias, particularidades y singularidades que caracterizan a las sociedades y países de nuestra América.

\section{Bibliografía}

Aboy Carlés, Gerardo. 2013. «De lo popular a lo populista o el incierto devenir de la plebs». En Las brechas del pueblo. Reflexiones sobre identidades populares y populismo, compilado por Gerardo Aboy Carlés, Sebastián Barros y Julián Melo, 17-40. Bs. As.: UNGS-UNDAV.

Alvarado, Mariana, Delmy Tania Cruz Hernández y Lisset Coba Mejía. 2020. «Feminismos en movimiento en América Latina y el Caribe. Intersecciones entre pensamiento y acción política». Millcayac 7(12): 11-24. https://revistas.uncu.edu.ar/ojs3/index.php/millca-digital/article/ view/3016/2178

Antón Sánchez, John. 2007. «Afrodescendientes: sociedad civil y movilización social en Ecuador». Journal of Latin American and Caribbean Anthropology 12,1: 233-245. 
Bajtín, Mijáil. 1982. Estética de la creación verbal. México D.F.: Siglo XXI.

Belloni, Paula y Andrés Wainer. 2014. «El rol del capital extranjero y su inserción en la América del sur posneoliberal». Problemas del Desarrollo 45(177): 87-112.

Chávez, Patricia y Dunia Mokrani. 2007. «Los movimientos sociales en la AsambleaConstituyent»". En Bolivia. Memoria, insurgencia $y$ movimientos sociales, compilado por Maristella Svampa y Pablo Stefanoni, 55-66. Bs. As.: CLACSO.

Blondiaux, Loic. 2013. «El nuevo espíritu de la democracia».En Actualidad de la democracia participativa. Bs. As.: Prometeo.

Bringel, Breno. 2017. «Crisis política y polarización en Brasil: de las protestas de 2013 al golpe de 2016"». En Protesta e indignación global. Los movimientos sociales en el nuevo orden mundial, compilado por Breno Bringel y Geoffrey Pleyers, 140-154. Bs. As.: CLACSO.

Bruno, Daniela, Ramiro Coelho y Mercedes Palumbo. 2017. «Innovación organizacional e institucionalización conflictiva de las organizaciones de la Economía Popular. El caso de la Confederación de Trabajadores de la Economía Popular (CTEP)». Argumentos 19: 90-119. https://publicaciones.sociales.uba.ar/index.php/argumentos/article/view/ $\underline{2766 / 2361}$

Castillo, Christian y Eduardo Castilla. 2015. «La década de los relatos: el ciclo kirchnerista desde la izquierda». Márgenes. Revista de Economía Política 1: 137-149.

Ceceña, Ana Esther. 2001.«Por la humanidad y contra el neoliberalismo. Líneas centrales del discurso zapatista». En Resistencias Mundiales. De Seattle a Porto Alegre, compilado por José Seoane y Emilio Taddei. Bs. As: CLACSO.

Coraggio, José Luis. 2014. «Otra política, otra economía, otras izquierdas». En Reinventar la izquierda en el siglo XXI, organizado por José Luis Coraggio y Jean Louis Laville, 35-84. Bs. As.: UNGS.

Coraggio, José Luis. 2018. «Potenciar la Economía Popular Solidaria: una respuesta al neoliberalismo». Otra Economía, 11(20): 4-18. https://www.revistaotraeconomia.org/index.php/otraeconomia/article/ view/14771/9360

Curiel, Ochy. 2007. «Crítica poscolonial desde las prácticas políticas del feminismo antirracista». Nómadas 26: 92-101.

De Ípola, Emilio y Juan Carlos Portantiero. 1981. «Lo nacional popular y los populismos realmente existentes». Nueva Sociedad 54: 7-18.

De Sena, Angélica y Florencia Chahbenderian. 2011. «Argentina ¿trabaja? Algunas reflexiones y miradas del plan 'Ingreso Social con Trabajo», Polis, 30. 
De Sousa Santos, Boaventura. 2010. Refundación del Estado en América Latina. Bs. As: Antropofagia.

De Sousa Santos, Boaventura. 2017. «Constitución y hegemonía. Luchas contra la dominación global», Chasqui. Revista Latinoamericana de Comunicación 136: 13-31.

Fair, Hernán. 2010. «Por una economía con un rostro humano. Crítica a la filosofía utilitarista neoliberal a partir del caso argentino». Persona $y$ Sociedad 24: 85-109.

Fair, Hernán. 2017. «Política, discurso y hegemonía. Etapas en la imposición del orden neoliberal y formas de resistencia en el agro local (1976 a la actualidad)». En Cuestión agraria y agronegocios en la región pampeana, compilado por Manuela Moreno y Guillermo de Martinelli, 17-69. Bernal: UNQ.

Fair, Hernán. 2020. «Fuerzas del capitalismo neoliberal, disputa hegemónica y construcción de alternativas en América Latina. Logros y limitaciones de los gobiernos posneoliberales y los movimientos sociales» Millcayac 7(13): 465-512. http://revistas.uncuyo.edu.ar/ojs3/index.php/millcadigital/article/view/2656/2760

Fernández, Blanca y Florencia Puente. 2012. «Configuración y demandas de los movimientos sociales hacia la Asamblea Constituyente en Bolivia y Ecuador». Íconos 44: 49-65.

Gaggero, Alejandro, Martín Schorr y Andrés Wainer. 2014. Restricción eterna. El Poder Económico durante el kirchnerismo. Bs. As.: Crisis.

Gaiger, Luiz Inácio. 2009. "«Antecedentes e expressões atuais da economia solidária». Revista Crítica de Ciências Sociais 84: 81-89. https://journals.openedition.org/rccs/401\#tocto1n2

García Linera, Álvaro. 2012. Las tensiones creativas de la revolución. Bs. As.: Luxemburg.

García Linera, Álvaro. 2015. Antología: Hacia el Gran Ayllu Universal. México: Altepl.

Giarracca, Norma y Miguel Teubal. 2006. «Democracia y neoliberalismo en el campo argentino. Una convivencia difícil». En La construcción de la democracia en el campo latinoamericano. Compilado por Hubert Grammont, 69-94. Bs. As.: CLACSO.

Goldfrank, Benjamin. 2011. «Los consejos comunales: ¿Avance o retroceso para la democracia venezolana?». Íconos 40: 41-55.

Gramsci, Antonio. 1984. Notas sobre Maquiavelo, sobre la política y sobre el Estado moderno. Bs. As.: Nueva visión.

Harvey, David. 2007. Breve historia del neoliberalismo. Madrid: Akal. 
Katz, Claudio 2008. Las disyuntivas de la izquierda en América Latina. Bs. As.: Luxemburg.

Klachko, Paula y Katu Arkonada. 2016. Desde abajo, desde arriba. De la resistencia a los gobiernos populares: escenarios y horizontes del cambio de época en América Latina. Bs. As.: Prometeo.

Laclau, Ernesto. 1993. Nuevas reflexiones sobre la revolución de nuestro tiempo. Bs. As.: Nueva visión.

Laclau, Ernesto. 2005. La razón populista. Bs. As.: FCE.

Laclau, Ernesto. 2014. «Prefacio a la edición inglesa». En Los fundamentos retóricos de la sociedad, Londres, 27 de diciembre de 2013, 11-20. Bs. As.: FCE.

Laclau, Ernesto y Chantal Mouffe. 2004. Hegemonía y estrategia socialista. Bs. As.: FCE.

Lao-Montes, Agustín. 2009. «Cartografías del campo político afrodescendiente en América Latina». Universitas Humanística 68: 207245.

López Castro, Natalia y Guido Prividera. 2011. Repensar la agricultura familiar. Bs. As.: CICCUS.

López Castro, Natalia. 2017. «Transformaciones sociales en el agro pampeano de las últimas décadas: concentración, persistencia de la producción familiar y su potencial aporte a un nuevo modelo de desarrollo». En Cuestión agraria y agronegocios en la región pampeana, compilado por Manuela Moreno y Guillermo de Martinelli, 259-289. Bernal: UNQ.

López Maya, Margarita. 2010. «Venezuela: once años de gestión de Hugo Chávez Frías y sus fuerzas bolivarianas (1999-2010)». Temas y debates 20: 197-226.

López Maya, Margarita. 2018. «Socialismo y comunas en Venezuela». Nueva Sociedad 274:59-70. https://static.nuso.org/media/articles/downloads/3.TC_Lopez_Maya_27 4.pdf

Macpherson, Crawford Brough. 1982. La democracia liberal y su época. Madrid: Alianza.

Maldovan Bonelli, Johanna. 2020. «Las relaciones laborales en el trabajo asociativo y autogestivo: reflexiones a partir del caso argentino». Astrolabio 24: 156-185. https://revistas.unc.edu.ar/index.php/astrolabio/ article/view/23513

Manin, Bernard. 1998. Los principios del gobierno representativo. Madrid: Alianza. 
Marticorena, Clara. 2013. «Relaciones laborales y condiciones de trabajo en la industria manufacturera durante la posconvertibilidad». En Argentina después de la Convertibilidad (2002-2011). Compilado por Juan Grigera, 135-162. Bs. As.: Imago mundi.

Modonesi, Massimo y Mónica Iglesias. 2016. «Perspectivas teóricas para el estudio de los movimientos sociopolíticos en América Latina: ¿cambio de época o década perdida?». De raíz diversa 3(5): 95-124. https://core.ac.uk/download/pdf/45358241.pdf

Ouviña, Hernán. 2009. «La autonomía urbana en territorio argentino. Apuntes en torno a la experiencia de las asambleas barriales, los movimientos piqueteros y las empresas recuperadas». En Argentina en pedazos. Luchas sociales y conflictos interburgueses en la crisis de la Convertibilidad, compilado por Alberto Bonnet y Adrián Piva, 115-143. Bs. As.: Peña Lillo.

Pateman, Carole. 2014. «Participación y teoría democrática». Bs. As.: Prometeo.

Retamozo, Martín. 2011. «Movimientos sociales, política y hegemonía en Argentina». Polis 28.

Revilla Blanco, Marisa. 2019. «Del 'Ni una más' al '\#Ni una menos': movimientos de mujeres y feminismos en América Latina». Política y Sociedad 56(1): 47-67.

Ruggeri, Andrés. 2014. Informe del IV relevamiento de Empresas Recuperadas en la Argentina. Bs. As.: Cooperativa Chilavert.

Sader, Emir. 2009. El nuevo topo. Los caminos de la izquierda latinoamericana. Bs. As.: Siglo XXI.

Schneider, Celeste y Yanina Welp. 2011. "¿Transformación democrática o control político? Análisis comparado de la participación ciudadana institucional en América delSur». Íconos 40: 21-39.

Seoane, José. 2012. «Neoliberalismo y ofensiva extractivista. Actualidad de la acumulación por despojo, desafíos de Nuestra América», Theomai 26. https://www.redalyc.org/pdf/124/12426097006.pdf

Svampa, Maristella. 2011. «Argentina, una década después. Del 'que se vayan todos' a la exacerbación de lo nacional-popular», Nueva Sociedad, 235. https://www.cetri.be/IMG/pdf/3794_1.pdf

Svampa, Maristella. 2012. "Consenso de los commodities, giro ecoterritorial y pensamiento crítico en América Latina». OSAL 32: 15-38.

Thwaites Rey, Mabel. 2010. «Después de la globalización neoliberal, ¿qué Estado en América Latina?», Cuadernos del Pensamiento Crítico Latinoamericano 32.

Wainer, Andrés y Martín Schorr. 2014. «Concentración y extranjerización del capital en la Argentina reciente: ¿Mayor autonomía nacional o 
incremento de la dependencia?». Latin American Research Review 49(3 ): 103-125. https://ri.conicet.gov.ar/bitstream/handle/11336/38324/ CONICET Digital Nro.0da4c135-0882-48e9-80cccd85c2dbf165_A.pdf?sequence=2\&isAllowed $=y$

Welp, Yanina. 2015. «Cuando todo lo sólido se desvanece en Twitter. Análisis del movimiento social \#yosoy132 (México 2012)». PostData 20(2): 417439.

Welp, Yanina. 2018. Todo lo que necesitás saber sobre las democracias del siglo XXI. Bs. As.: Paidós. 